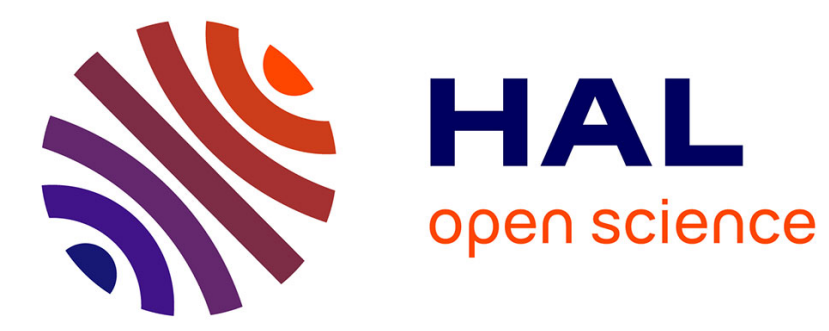

\title{
Agency within the context of pedagogies, epistemologies and the transformative curricula
}

Loïse Jeannin, Caroline Long, Phefumula Nyoni

\section{To cite this version:}

Loïse Jeannin, Caroline Long, Phefumula Nyoni. Agency within the context of pedagogies, epistemologies and the transformative curricula. Transformative Curricula, Pedagogies and Epistemologies: Teaching and Learning in Diverse Higher Education Contexts, 2021. hal-03322349

\section{HAL Id: hal-03322349 \\ https://hal.uca.fr/hal-03322349}

Submitted on 19 Aug 2021

HAL is a multi-disciplinary open access archive for the deposit and dissemination of scientific research documents, whether they are published or not. The documents may come from teaching and research institutions in France or abroad, or from public or private research centers.
L'archive ouverte pluridisciplinaire HAL, est destinée au dépôt et à la diffusion de documents scientifiques de niveau recherche, publiés ou non, émanant des établissements d'enseignement et de recherche français ou étrangers, des laboratoires publics ou privés. 


\section{Introduction \\ Agency within the context of pedagogies, epistemologies and the transformative curricula}

\section{LOÏSE JEANNIN, CAROLINE LONG and PHEFUMULA NYONI}

This book is the outcome of what began as a research seminar arranged by the Ali Mazrui Centre, University of Johannesburg, in collaboration with the Conservatoire National des Arts et Metiers (CNAM), two distinctive institutions whose philosophical perspectives on research in higher education came together. The aim of the Ali Mazrui Centre is to build institutional capacity in order to produce scholarly research that is multidisciplinary and policy-relevant, and to promote critical reflection and dialogue.

Ali Mazrui was a world-renowned academic with his roots in Africa. His work has indeed provoked critical thinking about the place of African academics in the world. Some of his statements resonate with the themes of this book. For instance, he argued that "to solve African problems we must think from the inside" (The Citizen, 2014). He strongly believed that "cultures of diversity" were a "blessing and an asset", and that a "really representative universal civilisation would incorporate much more of the heritage of the different cultures of the world" (Polylog, 2003).

The CNAM in Paris, and in particular the research centre Formation et Apprentissages Professionnels led by Anne Jorro, has a pertinent research focus on the development of professional identity through experience - experience which is interpreted subjectively and inter-subjectively. Researchers at the CNAM investigate training programme design, the transmission and circulation of knowledge, the dynamics of identity, as well as the links between professional learning and activity in the workplace and in training. These are studied at three levels: learning and learning processes set in context, individual learning paths, and organisational and institutional aspects of learning.

Transformative educational practices are essential in contemporary higher education in the African context, and, we may add, in the world context. Too often, the voices of individuals are not heard; in fact they do not speak, with the result that they do not benefit from opportunities to engage with the ideas that are offered. From the institutions' perspective, there is little to be gained from a class of silent and acquiescent students who are seeking only to imbibe what is being offered. It is critically important to have a curriculum that is relevant to their particular context - pedagogies that engage students in authentic interaction as envisaged by Freire and Dewey, and epistemologies that are reconceptualised to incorporate various sociocultural paradigms - if educators are to break the chains of "mainstream" education, not only in African contexts but globally.

How to transform practices, with this purpose in mind, is a real challenge for lecturers. The practices cannot be prescribed in a one-size-fits-all package, owing to higher educational institutional variations. The institutional differences reflect diversity in historical contexts and societal challenges, producing a wide variation of practices across countries and institutions. In trying to understand the dialogic and subjective nature of teaching, Higgins (2011:1) notes that from the point of view of working teachers, there are days when one lives up to ideals, and other days when one falls depressingly short of hope. In this context, individual 
agency provides resources to overcome the daily challenges faced by lecturers who aim to provide contextualised teaching content and relevant pedagogies for a wide spectrum of students.

Agency is effectively promoted between students and lecturers where diverse pedagogical and epistemological practices are at play. The central role of agency has also been emphasised in culturally diverse environments where students and lecturers tend to adjust to new socio-cultural settings (Jeannin, 2018; Tran, 2011). Agency is an important lens in understanding the relations between supervisors and students, especially during the thesis-writing processes that engage both body and mind in navigating enabling and constraining contexts.

Higgins (2011:2) maintains that in order to promote selfhood in students, teachers ought to 'bring to the table' their own achieved self-cultivation, their commitment to ongoing growth, together with their diverse practices, styles, and tricks for dealing with the multiple forces that deaden the self and distract individuals from authentic and deep learning. Long et al. (2017:6) support Higgins' view, contending that education is intrinsically about self-cultivation of teachers as much as it is for learners. In essence, the teachers' selfcultivation acts as a catalyst within the education process. Self-cultivation becomes crucial when one also explores how educators could possibly balance their obligations of self-regard with those of teaching, on one hand, and for students, how bodily dictates can be balanced with learning or thesis-writing processes on the other.

In this volume, we do not use the concepts of higher education and higher learning interchangeably. Biesta (2009) seeks to distinguish learning from education by emphasising the importance of being linguistically precise. The concept of education broadly denotes a set of activities, injunctions and content provided within an environment in which learning can take place. Learning is viewed as an individual process, referring to the personal and professional development of each individual. This involves changes that are the result of engagement with people's environments, implying an emphasis on the experiential component of the learning process (Biesta, 2009). To explore the concept of education in relation to agency, it follows that, in as much as one can educate someone and be educated by someone, it is impossible for one to 'learn' someone else, as reasoned by Biesta (2009:368). Education therefore ought to be viewed as referring to a specific setting in which learning takes place, with a specific set of roles and responsibilities governing the relations between educators and students.

Central to the arguments across various chapters in this volume is the concept of agency. According to Etelapelto, Vahasantanen, Hokka and Paloniemi (2013:48), despite the concept of agency gaining popularity in various disciplines and in policy circles, its core meaning is confusing and has not been explicitly defined. Etelapelto et al. (2013:48) determine that the ideals of agency have been loosely associated with dynamic striving, initiative-taking, or having an influence on one's own life situation. In evoking Giddens' notions of agency as an act that is intentionally perpetrated by actors, Etelapelto et al. (2013:49) add two conditions that 
need to be fulfilled: people must have the capacity to act upon their intentions, and they must have the power to evoke an event or to intervene in that particular event. Important in this approach to conceptualising agency is the consciousness of actors who can use their power to act differently and make a different choice. Adie, Willis and Van der Kleij (2018:2) emphasise that agency is represented by a shift from focus on the rational individual as agent, to embrace the complex interdependence of individual agency and social contexts. In this view, agency is not something that people can have or possess but is rather to be understood as something that people do or achieve.

African higher education institutions in general, and South African ones in particular, are faced with new demands, challenges and expectations in terms of pedagogy and epistemology. These are informed by diverse practices in epistemological access, inclusive education, and projects of transformation and decolonisation in higher learning. It can be argued that South Africa's current education transformation agenda needs to be understood in the context of the persistent apartheid legacy which continues to cast its long shadow not only on transformation but also on the shaping of teacher agency (Long, Graven, Sayed \& Lampen, 2017:3). Relevant to the diverse viewpoints presented in this volume is the post-apartheid government's transformation plan (Long et al., 2017:3) which has focused on introducing major changes in the area of teacher education governance and curricula.

The inevitability of diverse contexts points to the need of ensuring that the pedagogical approach used goes beyond notions of a 'normal' class or school, and provides for variety and change. This implies that the role of the teacher, researcher, mentor, or guide is not one that can be easily contained or prescribed. The student who comes into the higher education arena comes with a history, current constraints and opportunities, visions and goals. One view of the didactic contract (Brousseau) is that the professor's role is to make the student's voice clearer. Another view may be to work with the student's existing ideas and preoccupations and help the student contextualise these ideas into the larger academic space. Students expect to learn specific knowledge and develop skills that will prove useful in their professional and daily lives, learning through materials and pedagogies that are relevant to the environmental contexts in which they live (Gay, 2010; Ladson-Billings, 1995a, 1995b). Lecturers are expected to implement teaching pedagogies that promote social justice. Similarly, academics and emerging scholars pursue knowledge and pedagogies that are relevant to the diverse contexts within which they function. It follows that lecturers and researchers are expected to generate knowledge that will prove relevant for the socio-economic and cultural development of societies and for the reduction of historically grounded inequalities. This calls for authentic teaching and learning opportunities which are strongly expressed and grounded in the decolonisation movements in the African context at large, and specifically in South African universities (Le Grange, 2016).

In addition, the development of online programmes and teaching practices in higher education institutions that are designed for a variety of students, including those with disabilities, can bring about new 
learning opportunities (De Wit, 2011). The increasing diversity of university students (resulting from the massification of higher education and increasing student mobility worldwide) requires lecturers to develop inclusive and culturally responsive teaching practices to meet the learning needs of all their students, locally and across Africa. This is expected to begin with teacher education in institutions of higher learning, hence the need to articulate how student teachers and academic staff respond to these pedagogies. To accommodate diverse learning expectations and to facilitate the development of new pedagogies, professional development programmes for lecturers are being developed (Amzat \& Padilla-Valdez, 2017), while the conditions for their effectiveness are still debated. This book therefore presents insights concerning the regeneration of curricula and pedagogies in South Africa and beyond. These chapters reconsider the knowledge and pedagogies implemented at universities, scrutinising their relevancy for local and regional contexts. International trends and country-specific issues are also discussed. Researchers from different parts of the world examine different conceptual frameworks, research paradigms, theories and content to derive relevant policy recommendations.

The first section of this book (Chapters 2, 3 and 4) is founded on the theme of transformative educational practices in contemporary higher education. This theme indicates that pedagogical practices and the curriculum environment in which the current interface within higher education takes place, can be described as an outcome of a dynamic contradiction between global priorities on one hand, and national priorities on the other. The key feature of this section is an understanding of the nature of contemporary teaching and learning in its diverse forms.

Chapter 2, by Ledile Mohlakoane and Daryl Hewson, sets the tone with arguments that focus on how indigenous epistemologies can be drawn upon by hospitality management in general, with particular reference to food and beverage operations. The chapter presents critical insights towards understanding how indigenous South African culinary knowledge can be used to inform culinary curriculum development in higher education. Through a student-centred perspective, a wide range of perceptions of indigenous culinary knowledge are presented. Using Guerrero et al.'s (2012) study of 10 dimensions of traditional foods as a guide, explanations are offered of the significance of indigenous food to the students, and these are used to interpret the process of culinary curriculum design from an indigenous knowledge perspective. The design follows the key aspects of origin, health, and heritage, in shaping the diverse pedagogical interpretations surrounding indigenous food.

In Chapter 3, N'drie Assié Lumumba challenges Africa's colonial legacies, indicating that these have been detrimental to the continent, and have had a lasting impact, particularly in higher education. She explains that this is evident in the conspicuous absence of a student-centred pedagogy and the deliberate development of autonomous and critical thinking that prevails in African universities. The chapter is a reflective piece on the paradoxical and inadvertent convergence of aspects of Africa's educational tradition and French cultural practices and legacy, especially in relation to the notion of eloquence in teaching. The author argues that African institutions of higher education that inherited a French academic tradition tend to endure the negative 
impact of the convergence of two mutually reinforcing traditions of teacher-centred pedagogy. The chapter critically examines the history of an aspect of French pedagogy with an imprint of past colonial policies and practices that is inadvertently reinforced by an African pedagogy and its cultural values. In light of the contemporary African educational context advocating the promotion of democratic values, the author highlights an urgent need for transformation to a student-centred pedagogy, fostering critical thinking.

The use of language as a pedagogical tool through which teaching and learning is mediated is the subject of Chapter 4 by Epimaque Niyibizi and Juliet Perumal. In the Rwandan context where the medium of instruction for over a century was French, the shift to English in October 2008 as the sole medium of instruction is examined in terms of its advantages and challenges. With a focus on two universities located in the city of Kigali, the authors explore the perceptions of university lecturers and students regarding the prospects and challenges of implementing of the new policy between 2009 and 2017. Views that were expressed immediately after the announcement of the policy shift in 2009 are used in assessing notions of the policy's success in 2017 , nine years after its implementation.

The second section of this book (chapters 5 to 8 ) rests on the theme of pedagogical practices in diverse higher education contexts. This theme explores the increasing complexity of contemporary higher education contexts, which necessitates to choose appropriate pedagogical approaches to embrace the diversity of students' learning needs and interests.

How pedagogical practices currently embrace the transition to online learning is explored in Anneke Venter's Chapter 5. Using a social capital framework, the author research the nature of student collaborations in online learning and the potential benefits of such collaborations. Different forms of learning platforms are identified such as informal social learning platforms, social media, and external service providers, in addition to the use of 'myUnisa' as the official platform. The author observes that although students were initially hesitant to participate in the learning platforms, they reported positively on the benefits of collaborating with peers on myUnisa. The socio-affective benefits included the ability to develop confidence as a student, decreased feelings of isolation, boosting of morale as well establishing new networks. The chapter highlights how an imbalance in the socio-economic situations of Unisa students has resulted in an unequal distribution of resources in terms of access to materials and tutorial support, technologies, technological skills, and networks of learning. The conclusion of this chapter is that support is needed to integrate and strengthen the mechanisms that promote student usage of online platforms.

Boitumelo Khonou points out in Chapter 6 that the end of the apartheid era in South Africa necessitated the newly elected democratic government to create a more socially responsive education system in which all South African learners could access high quality, equitable and democratised education. The author highlights the need to adequately prepare teachers for teaching in diverse schooling contexts, a consequence of the growing diversity of learners in South African schools. Using the concept of culturally responsive teaching 
(CRT), emphasis is placed on the value of acquiring more accurate knowledge of the cultural and pedagogical experiences and contributions of different ethnic and racial groups. The author stresses the need for the provision of resources to aid teachers in multi-cultural classrooms, particularly those in poorly resourced schools, and for pre-service teachers to be further equipped with the requisite knowledge, attitudes and skills for dealing with a variety of students.

Chapter 7, written by Caroline Long and Gift Cheva, introduces the question of designing protocols that align with course goals, while at the same time being theoretically informed. The authors discuss how to evaluate both teacher assignments and student work, while monitoring the psychosocial context. In order to check the validity of the protocols, the authors analyse three assignment questions and two sets of responses from a moderately proficient and a competent student. In the process, the authors reflect on the extent to which the classroom environment enables or constrains agency from the perspective of one lecturer and two students. While acknowledging that the quality of teacher assignments can affect students' intellectual work, the authors posit that the classroom environment can equally enable or constrain agency. Through an ecological lens, they view agency not as an inherent feature of an individual, but rather as observable during interaction with the environment. Agency is therefore regarded as a necessary component of social transformation - which, in the case of teaching, is observed in the unfolding of the competencies and lives of individual students.

Loïse Jeannin and Emmanuel Ojo, in Chapter 8, explore the undervalued potential of CRT and differentiated instruction (DI) in improving economics teaching in South Africa. They contend that in the context of the ongoing debate surrounding the Africanisation of knowledge in South African universities, CRT and DI may enable economics lecturers to draw on the diversity of their students' own life experiences to anchor economics teaching in real-life problems and debates on authentic economic issues. Their call aims to strengthen the relevance of economics teaching at university. Through analysis of how the pedagogical principles of CRT and DI can be unpacked in the South African context, the authors pinpoint strategies to better engage learners in their classes by providing context-relevant content, authentic learning activities, and fair assessments. Drawing on students' intrinsic motivation, economics lecturers can thus offer a set of learning activities that can assist students to connect their learning to their socio-economic backgrounds and lived experiences.

The theme of the third section of this book is professional encounters in contemporary higher education contexts, and covers Chapters 9 to 11 . It presents questions related to the engagement into learning (engagement of the body and the mind). Some of the tensions between natural and social principles defining academic and professional experiences in diverse higher education contexts are captured under this theme. Experiences of various academics and professionals have shown that philosophical dictates relating to diverse pedagogies can be both complementary and contradictory. 
In Chapter 9, Anne Jorro and Elsa Chachkine explore the field of adult learning in terms of adults who are involved in studying for and writing doctorates. The authors offer insight into this experience, as being not just an intellectual engagement, but also involving the interplay of the body and emotions. For the authors, $\mathrm{PhD}$ involves adult learning, hence their exploration of the intellectual, emotional and bodily engagement of adults who are involved in studying for, and writing a $\mathrm{PhD}$. In addition to exploring the role of emotions in helping students to cope at a physical level with $\mathrm{PhD}$ dictates, the authors conclude that the changes which $\mathrm{PhD}$ students experience while writing their theses are driven by psychosocial factors which include commitment, self-confidence, and strategies for arranging the writing space.

Michael Cross's Chapter 10 presents some insights into the various features associated with supervising doctoral students in South Africa's high performance universities. The notions of pedagogy, context and agency and their influences on $\mathrm{PhD}$ supervision are explored.

In Chapter 11, Dennis Zami Atibuni contends that research can be viewed as a terminal assessment for learning. Drawing from literature, the author argues that postgraduate students who use mastery orientation in carrying out their research will engage in deep learning of both the theoretical and practical demands of the research process. In this case, what is learned is enduring. On the other hand, students who are performanceorientated in their research are likely to engage in surface learning, taking ethical shortcuts in order to have the work completed, presented, and passed. In this case, what is learned from the research process is not enduring, and the process serves as an assessment of temporary learning. Among other recommendations, the author proposes that institutional policies and faculty practices regarding research conduct should engender deep learning through mastery orientation, as opposed to performance-orientated surface learning, to foster research as an assessment for learning rather than as an assessment of learning.

Epistemological access and extended learning opportunities for students with diverse needs constitutes the theme of the fourth section of this book, covering Chapters 12 to 14 . Contributions to this section reflect how curricular and epistemological access, in addition to opportunities for teaching and learning, are provided for students in different African higher education contexts, and in South Africa in particular. The section presents narrative work and critical reviews of existing accounts relating to theoretically and methodologically grounded epistemologies and pedagogies.

In Chapter 12, Sibonokuhle Ndlovu probes the question of inclusion in post-apartheid South Africa, having noted spirited efforts to include formerly underprivileged people from diverse backgrounds in both the education and employment contexts. Using decolonial theory, the author analyses specific opportunities afforded to students with disabilities to enable them to access professional learning at institutions of higher learning, while at the same time exploring instances when they remain excluded despite these affordances. Insights are offered into the persistence of low throughput for formerly underprivileged social groups in higher learning, and into the exclusion of persons with disabilities from professional employment. The concept of 
'universal design in learning' is proposed as a way in which teaching and learning in higher education could be organised, so that students' diverse learning needs are embraced from the outset.

The issue of curriculum transformation to accommodate underprepared students in South Africa's higher education system is assessed by Phefumula Nyoni in Chapter 13. The chapter uses experiential data from a South African higher education institution to explore varied practices associated with extended curriculum programmes (ECPs) which the Council of Higher Education (2013) considers key in improving underprivileged students' academic access. Drawing from the view that individuals who are socially and economically disadvantaged are less likely to gain access to and successfully complete any form of higher education - particularly in the absence of relevant forms of support - the author uses the concept of agency to show how myths and related perceptions in practices associated with ECPs have had constraining effects on efforts to assist underprepared students. In some instances, the myths and related practices have been detrimental to the successful implementation of the programme, harming the students and consequently impinging on the broader success of the transformative agenda in higher education.

Chapter 14, written by Neema-Abooki and Tumwesigye, explores the way in which internationalisation of higher education has triggered quality assurance trends and responses, with specific reference to Makerere University in Uganda. The chapter examines varying trends of the internationalisation process and responses to quality assurance in the realm of teaching and learning. Since internationalisation has become one of the major drivers of change in higher education across the world, the authors ultimately caution universities in Africa to be wary of quality assurance as they respond to this drive in the context of matching globalisation trends.

\section{References}

Adie, L.E.; Willis, J. \& Van der Kleij, F.M. 2018. Diverse perspectives on student agency in classroom assessment. The Australian Association for Research in Education, 45:1-12.

Amzat, I. H. \& Padilla-Valdez, N. 2017. Teacher professional knowledge and development for reflective and inclusive practices. New York \& Oxon: Routledge.

Biesta, G. 2009. Good education: What it is and why we need it. Inaugural lecture 4 March 2009. Stirling: The University of Stirling Institute of Education.

De Wit, H. 2011. Trends, issues and challenges in internationalisation of higher education. Amsterdam, NL: Centre for Applied Research on Economics and Management, School of Economics and Management of the Hogeschool van Amsterdam, https://www.eurashe.eu/library/modernisingphe/mobility/internationalisation/WG4\%20R\%20Internationalization\%20Trends-Issues-andChallenges_Hans-de-Wit1.pdf 
Etelapelto, A.; Vahasantanen, K.; Hokka, P. \& Paloniemi, S. 2013. What is agency? Conceptualizing professional agency at work. Educational Research Review, 10:45-65.

Gay, G. 2010. Culturally responsive teaching: Theory, research, and practice. 2nd Edition. New York, NY: Teachers College Press.

Jeannin, L. 2017. The adaptation process of international lecturers in a South African university: The centrality of agency and collegiality. Journal of Research in International Education, 16(3):236-247. https://doi.org/10.1177/1475240917746035

Ladson-Billings, G. 1995a. But that's just good teaching! The case for culturally relevant pedagogy. Theory Into Practice, 34(3):159-165. https://doi.org/10.1080/00405849509543675

Ladson-Billings G. 1995b. Toward a theory of culturally relevant pedagogy. American Educational Research Journal, 32(3):465-491. https://doi.org/10.3102/00028312032003465

Le Grange, L. 2016. Decolonising the university curriculum. South African Journal of Higher Education, 30(2):1-12. https://doi.org/10.20853/30-2-709

Long, C.; Graven, M.; Sayed, Y. \& Lampen, E. 2017. Professional teacher agency: The South African context. Contemporary Education Dialogue, 14(1):1-17.

Polylog: Forum for intercultural philosophy 4. 2003. Universalism, global apartheid, and justice_Ali A. Mazrui in dialogue with Fouad Kalouche. Available at https://them.polylog.org/4/dma-en.htm [Accessed 11 November 2018].

Tran, L.T. 2011. Committed, face-value, hybrid or mutual adaptation? The experiences of international students in Australian higher education. Educational Review, 63(1):79-94. https://doi.org/10.1080/00131911.2010.510905 